\title{
Chronic Liver Disease and Mitochondrial Antibodies: A Family Study
}

\author{
J. G. WALKER \\ D. BATES, \\ D. DONIACH, \\ P. A. J. BALL, \\ S. SHERLOCK
}

British Medical fournal, 1972, 1, 146-148

\section{Summary}

Two sisters had primary biliary disease and associated autoimmune thyroiditis with high titres of mitochondrial and other autoantibodies. Their deceased mother possibly sufiered from similar disorders. In the same family two brothers had multiple autoimmune reactions, including mitochondrial antibodies, but liver function tests gave normal results. Ten other close relatives were investigated. Australia antigen was not found in the proband or her relatives.

\section{Introduction}

Reports of familial cirrhosis are not numerous. The older studies were reviewed by Maddrey and Iber (1964), who reported eight affected families. Aetiological factors were mostly obscure though it is generally agreed that the occurrence is uncommon except in Wilson's disease, haemochromatosis, and other metabolic disorders (McConnell, 1966). More recent work from Japan suggests that many familial cases may be attributed to persistent viral infection as the hepatitis-associated (Australia) antigen has been detected in some instances (Ohbayashi et al., 1971). Interest in the relation between autoimmunity and chronic liver disease initiated two family studies from Scandinavia: in one, Cavell and Leonhardt (1965) found hypergammaglobulinaemia and antinuclear antibodies (A.N.A.) in a proportion of maternal relatives of a young girl with lupoid hepatitis; in the other, Elling et al. (1966) reported hypergammaglobulinaemia and an increased incidence of A.N.A., rheumatoid factors, and thyroid autoantibodies in families of cirrhotic patients in whom these tests were positive.

Joske and Laurence (1970) reported a family in which five members had chronic liver disease, including two with lupus erythematosus (L.E.) cells, while eight others had raised serum immunoglobulin levels and positive latex or Wassermann reactions. Mitochondrial antibodies were not detected in seven members examined; smooth-muscle fluorescence was not studied. Pollak (1964), in a study on systemic lupus erythematosus, also mentioned positive A.N.A. in 8 out of 39 relatives of patients with chronic hepatitis.

Primary biliary cirrhosis is strongly associated with autoimmune phenomena (Walker and Doniach, 1971), and family studies in this disease have shown an increased incidence of mitochondrial and other serum autoantibodies (Feizi et al., 1972). Familial cases of this disease, however, do not seem to have been described. This paper reports a family in which two sisters had chronic biliary disease in association with autoimmune phenomena that were also present in several other members of the family.

\section{Middlesex Hospital, London W1P 9PG}

J. G. WALKER, M.D., M.R.C.P., Senior Registrar (Present appointment: Consultant Physician, St. Mary's Hospital, London W.2.)

D. BATES, M.B., B.CHIR., House Physician (Present appointment: Resident Medical Officer, National Heart Hospital, London W.7)

D. DONIACH, M.D., F.R.C.P., Reader in Immunopathology

P. A. J. BALL, M.D., F.R.C.P., Consultant Physician

Royal Free Hospital, London WC1X 8LF

S. SHERLOCK, M.D., F.R.C.P., Professor of Medicine

\section{Patients and Methods}

Patients and Relatives.-Fourteen members have been investigated, including the two affected sisters, their four living sibs, and the eight healthy offspring of the proband (see Family Tree).

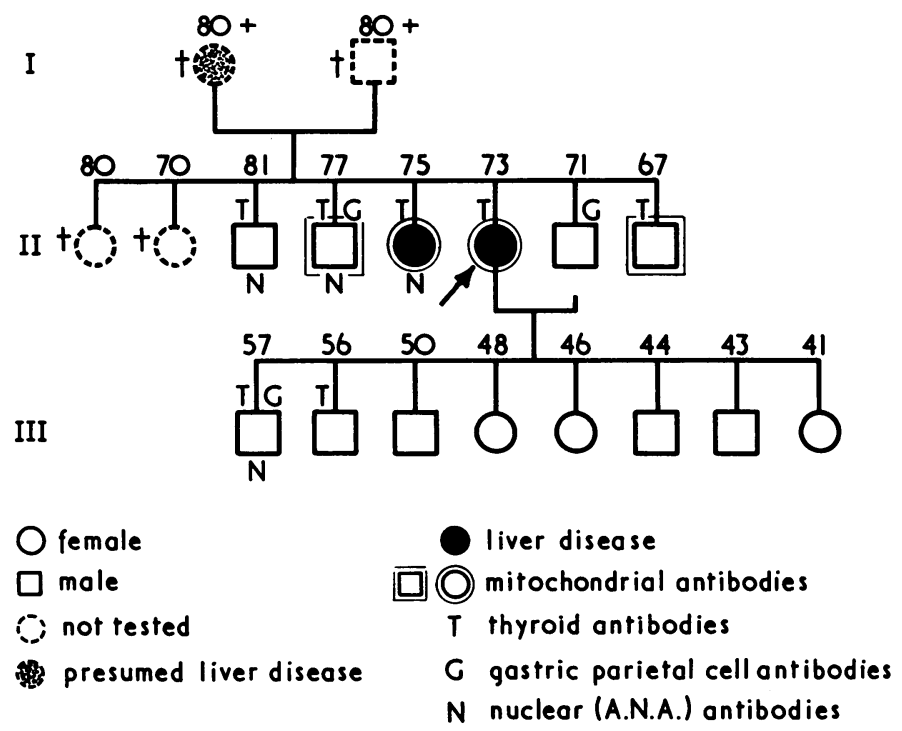

Family of patient with liver disease and mitochondrial antibodies.

Serological Methods.-Autoantibodies were detected by immunofluorescence, complement fixation (C.F.T.), and tanned red cell agglutination (T.R.C.) (Roitt and Doniach, 1969). Fluorescence titres were obtained with specific anti-IgG and anti-IgM conjugates. In the presence of mitochondrial antibodies it is difficult to assess the titre of organ-specific thyroid and gastric cytoplasmic antibodies, except if they happen to be of a different Ig class. In this family complement fixation tests with purified thyroid microsomes were probably organspecific; C.F.T. with rat kidney homogenate is often positive in patients with viral hepatitis and other liver disorders, and weak reactions, up to $1: 16$, are obtained in up to $5 \%$ of normal individuals. Australia antigen was looked for by double diffusion and counter-electrophoresis (Prince and Burke, 1970).

\section{Case 1}

In October 1968 a 73-year-old housewife complained of four months' pruritus and lack of energy. On examination she was well nourished and showed pigmentation of the skin. She was anicteric and there were no xanthomata or cutaneous stigmata of chronic liver disease. A smooth firm liver edge was palpable $3 \mathrm{~cm}$ below the costal margin. The spleen could not be felt and fluid retention was absent. There was no evidence of colitis. The thyroid gland was slightly enlarged and moderately firm, estimated weight $30 \mathrm{~g}$.

Investigations. - Hb $14.5 \mathrm{~g} / 100 \mathrm{ml}$; W.B.C. $7,000 / \mathrm{mm}^{3}$ (polymorphs $36 \%$, lymphocytes $57 \%$ ); platelets $125,000 / \mathrm{mm}^{3}$; prothrombin concentration $100 \%$; serum bilirubin $0.9 \mathrm{mg} / 100 \mathrm{ml}$; serum alkaline phosphatase $26-32 \mathrm{~K}$.A. units $/ 100 \mathrm{ml}$; aspartate transaminase (SGPT) 38-40 units/ml; serum albumin $3.4 \mathrm{~g}$ and globulin $4.7 \mathrm{~g} /$ $100 \mathrm{ml}$; serum IgG $1,000 \mathrm{mg}$, IgA $310 \mathrm{mg}$, and IgM $470 \mathrm{mg} / 100$ $\mathrm{ml}$; serum cholesterol $270 \mathrm{mg} / 100 \mathrm{ml}$; cholecystogram normal; 
Autoantibodies and Biochemical Tests of Liver Function in Family Members

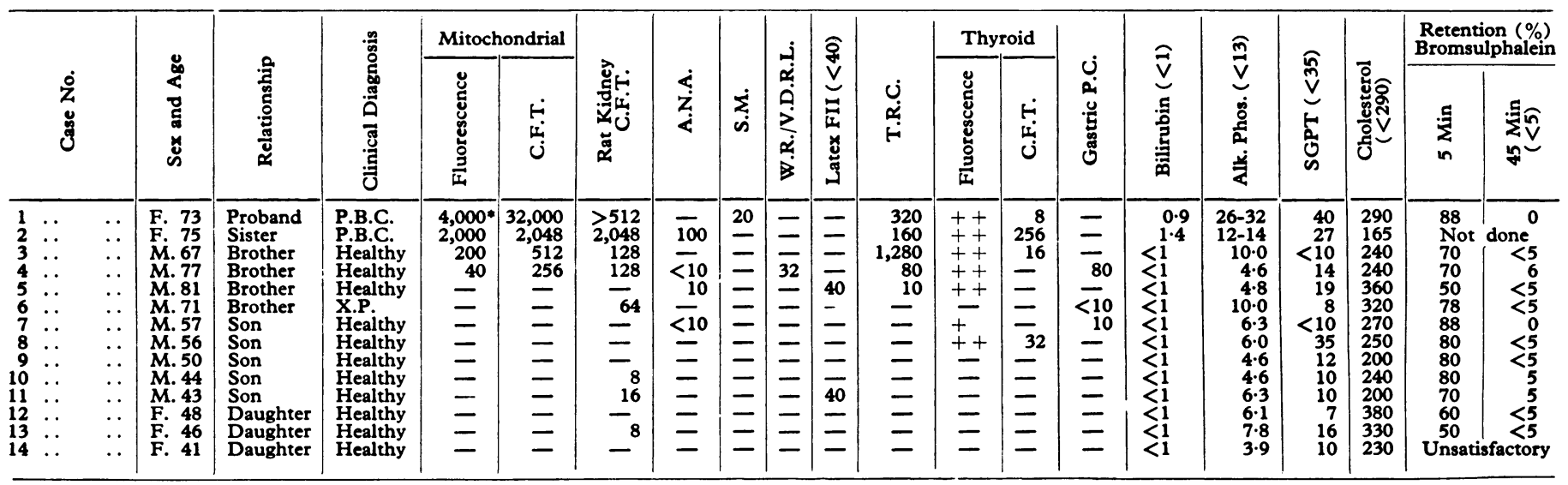

P.B.C. = Primary biliary cirrhosis. X.P. = Xanthelasma palpebrarum. S.M. $=$ Smooth muscle. $\quad$ P.C. $=$ Parietal cell.

- Numbers represent reciprocal of highest serum dilution giving a positive result.

Figures in parentheses represent upper limits of normal values.

barium swallow, no oesophageal varices. Serum antibody tests showed a mitochondrial immunofluorescence titre of 1:2,000, C.F.T. $1: 2,048$; thyroid antibodies were T.R.C. $1: 20$, C.F.T. $1: 8$, A.N.A. was negative, and smooth-muscle fluorescence was $1: 20$. On histological examination a needle biopsy specimen of the liver showed collapse of the reticulin framework in the periportal regions with increased fibrosis. A dense lymphocytic infiltrate was seen in the portal triads and some parenchymal cell necrosis in relation to this infiltrate. Small scattered areas of cell necrosis were found within the lobules. Bile ducts were visible and did not show duct cell necrosis. Despite this, a diagnosis of early primary biliary cirrhosis was made.

During the next three years the patient remained well apart from mild itching which was successfully controlled with cholestyramine and antihistamines. Her weight was constant and signs of hepatic decompensation have not developed. Biochemical tests have not changed. Mitochondrial antibodies have persisted in high titres: fluorescence $1: 4,000$, C.F.T. $1: 32,000$. The thyroid gland was slightly larger and was firm with an irregular surface; however, thyroid function was normal and serum thyroxine level was $92 \mathrm{ng} /$ $\mathrm{ml}$. Thyroglobulin antibody titres rose to T.R.C. 1:320; the C.F.T. was still low. Australia antigen was not detected.

\section{Case 2}

In 1963 the 75-year-old sister of Case 1 first developed jaundice associated with abdominal pain. This faded slowly over several months. In 1965 recurrence of abdominal pain led to laparotomy. The liver appeared to be enlarged and nodular and a small pigment stone was removed from the gall bladder. Liver histology showed intact lobular architecture with portal scarring and infiltration with lymphocytes and plasma cells. Bile ducts and ductules were inconspicuous but there was no cholestasis. After the intervention she felt generally unwell; she had palmar erythema and increased skin pigmentation. The liver was clinically enlarged but the spleen was inpalpable. A small nodular goitre was noted.

Investigations.-In 1965: Hb $12.2 \mathrm{~g} / 100 \mathrm{ml}$; W.B.C. $5,200 /$ $\mathrm{mm}^{3}$; platelets $134,000 / \mathrm{mm}^{3}$; serum bilirubin $0.5 \mathrm{mg} / 100 \mathrm{ml}$; alkaline phosphatase 12 K.A. units $/ 100 \mathrm{ml}$; SGPT 10 units $/ \mathrm{ml}$; serum albumin $2.1 \mathrm{~g}$ and globulin $5.2 \mathrm{~g} / 100 \mathrm{ml}$; electrophoresis showed raised gamma fraction; serum cholesterol $165 \mathrm{mg} / 100 \mathrm{ml}$. L.E. cell and Wassermann reactions were negative. An intravenous cholangiogram showed a normal common bile duct. Serologically she had a mixture of thyroid specific (microsomal fluorescence pattern to $1: 100$, T.R.C. $1: 80$ ) and mitochondrial antibodies (fluorescence to $1: 2,000$ ) which were of both $\mathrm{IgG}$ and IgM classes. At this time A.N.A. was negative. During the next six years physical signs and biochemical tests remained unchanged. In May 1971 serum bilirubin was less than $0.5 \mathrm{mg}$; alkaline phosphatase 14 units, and SGPT 22 units; albumin $3.6 \mathrm{~g}$ and gammaglobulin $2.3 \mathrm{~g} / 100 \mathrm{ml}$.

\section{Family History}

Both parents were dead. The mother had undergone operation for jaundice and suspected gall stones at the age of 60 but no calculi had been found and she had suffered continued dyspeptic symptoms, finally dying some 20 years later. There was no history of liver disorders in any other family members. One sister died of asthma and another of cancer of the oesophagus. All other first-degree relatives were interviewed and examined. One brother aged 67 had pruritus, earlier diagnosed as due to industrial dermatitis, which was cured. Another brother aged 71 had xanthelasma palpebrarum but no pruritus and was otherwise well. None of the relatives had jaundice or hepatomegaly and all were in good health. Results of biochemical and autoantibody studies are shown in the Table.

Liver function tests were normal except for a mildly raised bromsulphalein retention of $6 \%$ at 45 minutes in a brother aged 77 (Case 4 in the Table), who had a moderate titre of mitochondrial antibodies (fluorescence 1:40 mostly IgM; C.F.T. 1:256), weakly positive A.N.A., thyroid and gastric specific antibodies of IgG class, and a biological false-positive Wassermann reaction with V.D.R.L. agglutination titre of 1:32. Another brother (Case 3) showed mitochondrial fluorescence of $1: 200$ of both IgG and IgM classes and C.F.T. of $1: 512$. His serum contained thyroid antibodies (T.R.C. $1: 1,280$, C.F.T. $1: 16$ ) but there was no clinical thyroid disease. Serological tests in the two positive brothers were repeated after an interval of two and a half years with substantially unaltered results. Both remained clinically well. The two other brothers had no mitochondrial antibodies but showed low titres of A.N.A., rheumatoid factor, and thyroid antibodies in one case and C.F.T. to 1:64 with rat kidney, along with low-titre gastric parietal cell fluorescence in the other. The eight healthy offspring showed only traces of antibodies (see Table). Australia antigen was not detected in eight relatives tested.

\section{Discussion}

The proband presented with insidious pruritus, pigmentation of the skin, and hepatomegaly, all compatible with early primary biliary cirrhosis. In the sister the picture was complicated by attacks of pain suggestive of biliary colic. This, however, is not uncommon in patients who on follow-up prove to have primary biliary disease (Block et al., 1969). In neither patient, however, did hepatic histology show the bile-duct necrosis and granulomata typical of primary biliary cirrhosis (Scheuer, 1968). In both cases the liver showed pronounced portal inflammation with mononuclear cell infiltration and piecemeal necrosis of the limiting-cell plates in the absence of an established cirrhosis. High levels of mitochondrial antibodies are most characteristic of primary biliary cirrhosis but they also occur in active chronic hepatitis (Doniach et al., 
1966) and in some middle-aged women presenting with cryptogenic cirrhosis (Ross et al., 1972).

The two patients in the present family did not show the typical clinical picture of either active chronic hepatitis or cryptogenic cirrhosis and they have not progressed to hepatic decompensation even after long follow-up. Similar lack of evidence of progression may be seen in the subclinical hepatitis associated with collagenosis or thyroiditis and mitochondrial antibodies in the serum (Walker et al., 1970). It is of interest that both our patients had a goitre and thyroid antibodies. The history in the mother was similar to that in the sister of the proband but in the absence of laboratory or histological information the nature of her illness remains obscure.

None of the relatives examined had clinical evidence of hepatic or thyroid disorder. One of the brothers with mitochondrial antibodies had mildly raised bromsulphalein retention, but in the other 11 relatives biochemical tests were normal. Liver histology was not available and no conclusions can be reached regarding the possibility of subclinical hepatic lesions. Besides the mitochondrial reactions half of the family members had thyroid antibodies, and one brother had a biological false-positive reaction for syphilis. This may be associaated with collagenosis (Doniach et al., 1970) and sometimes with subclinical hepatitis (Walker et al., 1970).

The family reported illustrates the clustering of mitochondrial and other tissue antibodies and clinical liver disease akin to primary biliary cirrhosis occurring in association with thyroid autoimmunity. None of the members had the Australia antigen in the serum and it is unlikely that the virus of longincubation hepatitis plays any part in the pathogenesis of primary biliary cirrhosis (Doniach et al., 1971). Of the 27 families studied by Feizi et al. (1972), in only one other was there a parent with possible cirrhosis, though $7 \%$ of the relatives had mitochondrial antibodies, as compared with less than $1 \%$ in the general hospital population.

\section{References}

Block, M. A., LoGrippo, G. A., and Fox, T. A. (1969). American fournal of Surgery, 117, 69.

Cavell, B., and Leonhardt, T. (1965). Acta Medica Scandinavica, 177, 751.

Doniach, D., Roitt, I. M., Walker, J. G., and Sherlock, S. (1966). Clinical and Experimental Immunology, 1, 237.

Doniach, D., Delhanty, J., Lindqvist, H. J., and Catterall, R. D. (1970). Clinical and Experimental Immunology, 6, 871.

Doniach, D., Del Prete, S., Dane, D. S., and Walsh, J. H. (1971). Canadian Medical Association fournal. In press.

Elling, P., Ranlov, P., and Bildsoe, P. (1966). Acta Medica Scandinavica, $179,527$.

Feizi, T., Naccarato, R., Doniach, D., and Sherlock, S. (1972). Clinical and Experimental Immunology. In press.

Joske, R. A., and Laurence, B. H. (1970). Gastroenterology, 59, 546.

McConnell, R. B. (1966). The Genetics of Gastrointestinal Disorders, p. 200, London, Oxford University Press.

Maddrey, W. C., and Iber, F. L. (1964). Annals of Internal Medicine, 61,

Ohbayashi, A., Mayumi, M., and Okochi, K. (1971). Lancet, 1, 244.

Pollak, V. E. (1964). New England fournal of Medicine, 271, 165.

Prince, A. M., and Burke, K. (1970). Science, 169, 593.

Roitt, I. M., and Doniach, D. (1969). Manual of Autoimmune Serology. Geneva, World Health Organization.

Ross, A., Scheuer, P. J., Fox, R. A., Sherlock, S., and Doniach, D. (1972). In preparation.

Scheuer, P. J. (1968). Liver Biopsy Interpretation, p. 22. London, Baillière, Tindail and Cassell.

Walker, J. G., and Doniach, D. (1971). In Immunology of the Liver, ed. M. Smith and R. S. Williams, p. 55. London, Heinemann. Walker, J. G., Doniach, D., and Doniach, I. (1970). Quarterly fournal of
Medicine, 39, 31.

\title{
Effect of Rifampicin and Isoniazid on Liver Function
}

\author{
SATINDER LAL， S. N. SINGHAL， D. M. BURLEY， G. CROSSLEY
}

British Medical fournal, 1972, 1, 148-150

\section{Summary}

The effects of rifampicin and isoniazid on liver function have been studied in 63 patients with pulmonary tuberculosis; $29 \%$ showed abnormalities of serum aspartate aminotransferase (SGOT) and a similar percentage abnormalities of serum bilirubin. These usually occurred during the first 12 weeks of therapy. The average duration of the abnormalities was $14 \frac{1}{2}$ days, irrespective of whether treatment was interrupted or not.

The relationship between raised SGOT and acetylator phenotype in a small number of patients suggests that those with raised SGOT are usually slow acetylator phenotypes. It seems that hepatic reactions in patients with previously normal liver function are usually mild and non-specific. However, patients who continue with rifampicin should be kept under close biochemical observation.

General Hospital, Bury, Lancashire

SATINDER LAL, M.B., B.S., F.R.C.P., Consultant Physician

S. N. SINGHAL, M.B., B.S., Clinical Assistant, Chest Unit

G. CROSSLEY, F.I.M.L.T., Biochemist

CIBA Laboratories, Horsham, Sussex

D.-M. BURLEY, M.B., B.S., Head of Medical Services

\section{Introduction}

Numerous reports have now been published showing rifampicin to be a potent antituberculous drug in both animal and human studies, comparable with isoniazid in its activity (Grumbach and Rist, 1967; Pines et al., 1967; Cannetti et al., 1968; Verbist and Gyselen, 1968; Gyselen et al., 1969; Dormer and Salinger, 1971; Newman et al., 1971; Nitti et al., 1971; Pines, 1971). In contrast with streptomycin it is effective orally, and it is much more palatable than para-aminosalicylic acid. Its use in combination with isoniazid, therefore, promises to be an ideal regimen. Initial studies with rifampicin in combination with other agents indicated that in the early weeks of therapy transient rises in serum bilirubin might occur, together with small changes in liver enzyme tests, but it was felt that these could be explained because the principal excretion pathway for the antibiotic was through the biliary tract, and there was direct competition with the excretion of bilirubin (Cohn, 1969). Overt liver damage from rifampicin was rare, though preexisting liver damage could be aggravated (Lesobre et al., 1969).

We now describe our experience of hepatic reactions from treating 63 patients ( 39 males and 24 females aged 8 to 80 years) suffering from pulmonary or lymph-node tuberculosis with, initially, a triple drug regimen including rifampicin. All were treated with streptomycin $0.75 \mathrm{mg}$ daily, isoniazid $300 \mathrm{mg}$ daily, and rifampicin $450 \mathrm{mg}$ in patients weighing less than $50 \mathrm{~kg}$ or $600 \mathrm{mg}$ in patients weighing $50 \mathrm{~kg}$ or more. If sensitivity testing showed that the patient's organisms were sensitive to rifampicin and isoniazid then the streptomycin was dropped, usually between the 8 th and 12 th weeks of therapy. 